\title{
In vivo potency of different ligands on voltage-gated sodium channels
}

\author{
Arpad Safrany-Fark ${ }^{\mathrm{b}}$, Zita Petrovszki ${ }^{\mathrm{c}}$, Gabriella Kekesi ${ }^{\mathrm{a}}$, Peter Liszli ${ }^{\mathrm{a}}$, Gyorgy Benedek ${ }^{\mathrm{a}}$, \\ Csilla Keresztes $^{\mathrm{d}}$, Gyongyi Horvath ${ }^{\mathrm{a}, *}$ \\ a Department of Physiology, Faculty of Medicine, University of Szeged, Dóm tér 10, H-6720 Szeged, Hungary \\ ${ }^{\mathrm{b}}$ Department of Orthodontics and Pediatric Dentistry, Faculty of Dentistry, University of Szeged, Tisza L. krt. 64, H-6720 Szeged, Hungary \\ c Institute of Physical Education and Sport Science, Juhász Gyula Faculty of Education, University of Szeged, Hattyas sor 10, H-6725 Szeged, Hungary \\ ${ }^{\mathrm{d}}$ Department of Medical Communication and Translation, Faculty of Medicine, University of Szeged, Szentháromság u. 5, H-6720 Szeged, Hungary
}

\section{A R T I C L E I N F O}

\section{Article history:}

Received 24 February 2015

Received in revised form

19 May 2015

Accepted 20 May 2015

Available online 29 May 2015

\section{Keywords:}

Anandamide

Capsaicin

Local anesthetic drugs

Motor nerves

Nisoxetine

Voltage-gated sodium channels

Chemical compounds studied in this article:

Lidocaine (PubChem CID: 3676)

Bupivacaine (PubChem CID: 2474)

Ropivacaine (PubChem CID: 175805)

Nisoxetine (PubChem CID: 134453)

Arachidonic acid (PubChem CID: 444899)

Anandamide (PubChem CID: 5281969)

Capsaicin (PubChem CID: 1548943)

QX-314 (PubChem CID: 3925)

Ketamine (PubChem CID: 3821)

Xylazin (PubChem CID: 5707)

\section{A B S T R A C T}

The Ranvier nodes of thick myelinated nerve fibers contain almost exclusively voltage-gated sodium channels $\left(\mathrm{Na}_{\mathrm{v}} \mathrm{s}\right)$, while the unmyelinated fibers have several receptors (e.g., cannabinoid, transient receptor potential vanilloid receptor 1 ), too. Therefore, a nerve which contains only motor fibers can be an appropriate in vivo model for selective influence of $\mathrm{Na}_{\mathrm{v}} \mathrm{s}$. The goals were to evaluate the potency of local anesthetic drugs on such a nerve in vivo; furthermore, to investigate the effects of ligands with different structures (arachidonic acid, anandamide, capsaicin and nisoxetine) that were proved to inhibit $\mathrm{Na}_{\mathrm{v}} \mathrm{s}$ in vitro with antinociceptive properties.

The marginal mandibular branch of the facial nerve was explored in anesthetized Wistar rats; after its stimulation, the electrical activity of the vibrissae muscles was registered following the perineural injection of different drugs.

Lidocaine, bupivacaine and ropivacaine evoked dose-dependent decrease in electromyographic activity, i.e., lidocaine had lower potency than bupivacaine or ropivacaine. QX-314 did not cause any effect by itself, but its co-application with lidocaine produced a prolonged inhibition. Nisoxetine had a very low potency. While anandamide and capsaicin in high doses caused about 50\% decrease in the amplitude of action potential, arachidonic acid did not influence the responses.

We proved that the classical local anesthetics have high potency on motor nerves, suggesting that this method might be a reliable model for selective targeting of Navs in vivo circumstances. It is proposed that the effects of these endogenous lipids and capsaicin on sensory fibers are not primarily mediated by Navs.

(c) 2015 Elsevier B.V. All rights reserved.

\section{Introduction}

The nodes of Ranvier of myelinated axons have voltage-gated sodium channels $\left(\mathrm{Na}_{\mathrm{v}} \mathrm{s}\right)$ with high density to produce saltatory conduction (Bucher and Goaillard, 2011; Salzer, 2002). In vitro data have proved that besides the classic local anesthetic drugs, several

Abbreviations: AA, arachidonic acid; AEA, anandamide (arachidonoyl ethanolamide); EMG, electromyography; TRPV1, transient receptor potential vanilloid 1;

$\mathrm{Na}_{\mathrm{v}}$, voltage-gated sodium channel

* Corresponding author. Fax: +36 62545842 .

E-mail addresses: safrany.arpad@stoma.szote.u-szeged.hu (A. Safrany-Fark), petrovszki.zita@med.u-szeged.hu (Z. Petrovszki),

kekesi.gabriella@med.u-szeged.hu (G. Kekesi), lp@med.u-szeged.hu (P. Liszli), benedek.gyorgy@med.u-szeged.hu (G. Benedek),

keresztes.csilla@med.u-szeged.hu (C. Keresztes),

horvath.gyongyi@med.u-szeged.hu (G. Horvath). ligands with different structures (such as arachidonic acid: AA, anandamide: AEA, capsaicin or nisoxetine) can inhibit $\mathrm{Na}_{\mathrm{v}} \mathrm{s}$, but no in vivo data are available in this respect (Hennings et al., 1999; Lundbaek et al., 2005; Nicholson et al., 2003). Capsaicin is a potent activator of transient receptor potential vanilloid receptor 1 (TRPV1), while AEA activates both the cannabinoid and TRPV1 receptors (Di Marzo et al., 2000; Mechoulam et al., 1995). These receptors can be found in sensory fibers but not in motor ones; therefore, the effects of these ligands on sensory neurons may be the sum of the changes in the activity of these different systems (Petsche et al., 1983; Weller et al., 2011). Nisoxetine, a norepinephrine reuptake inhibitor, has a local anesthetic effect, which might be related to its $\mathrm{Na}_{\mathrm{v}}$ blocking effect (Chen et al., 2012; Yokogawa et al., 2002). When the ligands are applied on mixed nerves, it cannot be excluded that the motor responses were influenced by actions on sensory fibers, at least indirectly, through 
reflex arches. These ligands can also inhibit voltage-gated potassium channels with very low potencies (Boland and Drzewiecki, 2008; Borchard and Drouin, 1980; Dubois, 1982). Since these channels are required for the repolarization, their inhibition enhances the excitability of the nerves (Krishnan et al., 2009; Matsumoto et al., 2010). Thus, a nerve having only myelinated motor fibers (e.g., marginal mandibular branch of the facial nerve, which controls the movement of mystacial vibrissae) can be an appropriate model for selective influence of $\mathrm{Na}_{\mathrm{v}} \mathrm{S}$ in vivo circumstances (Fundin et al., 1994; Semba and Egger, 1986). Tertiary amine local anesthetics block action potentials by inhibiting $\mathrm{Na}_{\mathrm{v}} \mathrm{S}$ from inside the nerve membrane (Butterworth and Strichartz, 1990; Frazier et al., 1970). The hydrophilic lidocaine derivative, QX-314, is incapable of diffusion through the membrane lipids in myelinated nerve fibers (Strichartz, 1973), but it can enter into the cytoplasm through activated TRPV1 channels leading to the preferential block of $\mathrm{Na}_{\mathrm{v}} \mathrm{S}$ in nociceptive fibers (Binshtok et al., 2007; Lim et al., 2007). Furthermore, QX-314 can enhance the efficacy of local anesthetics on sensory and motor functions applied to the mixed, perisciatic nerve (Binshtok et al., 2009; Roberson et al., 2011).

Our hypothesis was that if the local anesthetic drugs inhibit the signal conduction in the marginal mandibular branch of the facial nerve, this in vivo model can be used to characterize the $\mathrm{Na}_{\mathrm{v}} \mathrm{S}$ blocking potency of different ligands. The first goal was to set up and validate the model by three classical local anesthetics: lidocaine, bupivacaine and ropivacaine. It was also planned to investigate the potency of QX-314 alone and in combination with lidocaine; hereafter, to determine the effects of AA, AEA, capsaicin, and nisoxetine in order to reveal the potential role of $\mathrm{Na}_{\mathrm{v}} \mathrm{S}$ in their antinociceptive properties after perineural administration.

\section{Material and methods}

All experiments were carried out with the approval of the Hungarian Ethical Committee for Animal Research (Registration number: XIV/3754/2012). Wistar rats were anesthetized with an intraperitoneally injected mixture of ketamine $(72 \mathrm{mg} / \mathrm{kg})$ and xylazine $(8 \mathrm{mg} / \mathrm{kg})$, and facial area was shaved. The marginal mandibular branch of the facial nerve was explored at buccal level, and it was wrapped around with a unipolar wire electrode $(0.1 \mathrm{~mm})$ for electrical stimulation to induce the whisker movement. The ground electrode was placed close to the nerve and muscle. The stimulations with rectangular biphasic pulses of constant current were delivered through a stimulator with a supramaximal stimulus ( $1 \mathrm{~mA}$ for $250 \mu \mathrm{s}$ ). Electromyograph (EMG) activities after a single stimulus were recorded with unipolar needle electrodes placed into the whisker area of the rats. EMG recordings were amplified (Model 1700 Differential AC Amplifier, A-M Systems, Carlsborg WA), sampled at $20 \mathrm{kHz}$ with an A/D board, filtered ( $100 \mathrm{~Hz}$ to $5 \mathrm{kHz}$ ), and stored on a computer running software. The maximal amplitude was determined as a difference between the highest positive and lowest negative peak of the compound action potential. Amplitudes and peak-latencies (if there were any) were analyzed.

\subsection{Drugs}

The following drugs were administered: lidocaine (MW: 234.33; Lidocaine; Egis Pharmaceuticals PLC, Budapest, Hungary), bupivacaine (MW: 288.43; Actavis, Weston, Florida, USA), ropivacaine (MW: 274.40; Naropin, AstraZeneca, London, United Kingdom), anandamide (AEA; MW: 347.53), arachidonic acid (AA; MW: 304.47), QX-314 (MW: 263.40), all three from Sigma-Aldrich, Budapest, Hungary, nisoxetine hydrochloride (MW: 307.82; Tocris, Budapest, Hungary) and capsaicin (MW: 305.40; Plantakem Kft.,
Sándorfalva, Hungary). AA was dissolved in 10\% ethanol, AEA was dissolved in $10 \%$ ethanol $+4 \%$ Tween 80 , and capsaicin in $10 \%$ ethanol $+10 \%$ Tween 80 . QX-314 was dissolved in phosphate buffered saline (at $\mathrm{pH}=7.4$ ) (Liu et al., 2011). All the stock solutions were further diluted with saline.

\subsection{Experimental protocol}

After 3 consecutive determinations of EMG activities (baseline) with 2 min intervals, the effects of the different ligands were investigated. Drugs were administered perineurally distal to the stimulating electrode in $20 \mu \mathrm{L}$ volume. The applied doses were 21.4, 85.5, $213.7 \mathrm{nmol}(5,20,50 \mu \mathrm{g})$ for lidocaine; 17.3, 69.3, $173.4 \mathrm{nmol}(5,20,50 \mu \mathrm{g})$ for bupivacaine; $18.2,72.9,182.2 \mathrm{nmol}(5$, $20,50 \mu \mathrm{g})$ for ropivacaine; $184.3,368.5,737.0 \mathrm{nmol}(50,100$, $200 \mu \mathrm{g})$ for nisoxetine; 328.4, 656.8, $1313.6 \mathrm{nmol}(100,200$, $400 \mu \mathrm{g})$ for $\mathrm{AA} ; 72,288,576,1152 \mathrm{nmol}(25,100,200,400 \mu \mathrm{g})$ for AEA; 331.5, 663, $1326 \mathrm{nmol}(125,250,500 \mu \mathrm{g})$ for capsaicin. As regard QX-314, one high dose $(100 \mu \mathrm{g}=380 \mathrm{nmol})$ was used by itself. Because of the solubility of QX-314 in the applied volume, $190 \mathrm{nmol}(50 \mu \mathrm{g})$ was applied together with $21.4 \mathrm{nmol}(5 \mu \mathrm{g})$ or $85.5 \mathrm{nmol}(20 \mu \mathrm{g})$ lidocaine in combinations.

The measurements were repeated $30,60,90,120 \mathrm{~s}$ after the administration, and then in $2 \mathrm{~min}$ intervals for $30 \mathrm{~min}$ in total. The mean values between $0.5-2,4-10,12-20$ and $22-30$ min intervals were analyzed as $1 \mathrm{st}, 2 \mathrm{nd}$, 3rd and 4 th time periods. The number of animals in the different groups was 6-10.

\subsection{Statistical analysis}

Data are presented as means \pm S.E.M. Amplitudes of EMG activity were normalized by calculating the percentage change from baseline (mean of the 3 baseline values) for each post-injection data point by the following formula:

Relative amplitude of EMG activity (\%)=(observed amplitude/ baseline amplitude) $\times 100$.

Therefore, $100 \%$ means no effect of the drug on the amplitude of EMG activity, while 0\% means that there is no EMG response after the stimulus.

The area under the curve (AUC) values were obtained by calculating the area during the $30 \mathrm{~min}$ period following the injection to construct dose response curves for the different ligands. $\mathrm{AUC}_{\mathrm{min}}$ (0) value would mean the complete disappearance of EMG responses, while $A U C_{\max }(2800)$ would mean the $100 \%$ value of the amplitudes of action potentials (no drug effect). The mean AUC values were used for linear regression analysis (least square method) to determine the effective dose $50\left(\mathrm{ED}_{50}\right)$ values with $95 \%$ confidence intervals, which is equivalent to the dose that yielded $50 \%$ decrease in the amplitude of action potentials for the whole period $\left(\left[\mathrm{AUC}_{\min }+\mathrm{AUC}_{\max }\right] / 2=1400\right)$.

The time-course effects were examined by repeated measurement of ANOVA. The post-hoc comparison was calculated by using the Newmann-Keuls test $(P$ value $<0.05$ was considered significant). Statistical analyses were performed with STATISTICA for Windows version 12 (Statistica, Inc., Tulsa, Oklahoma, USA) and GraphPad Prism (GraphPad Software, Inc., La Jolla, California, USA) softwares.

\section{Results}

Marginal mandibular motor nerve stimulations produced EMG activity with visible whisker movements. The latency and the amplitude of EMG responses were stable during the investigated period in the vehicle treated groups (Fig. 1A). The latency of the first positive peak appeared at $1.9 \pm 0.02 \mathrm{~ms}$, while the second 

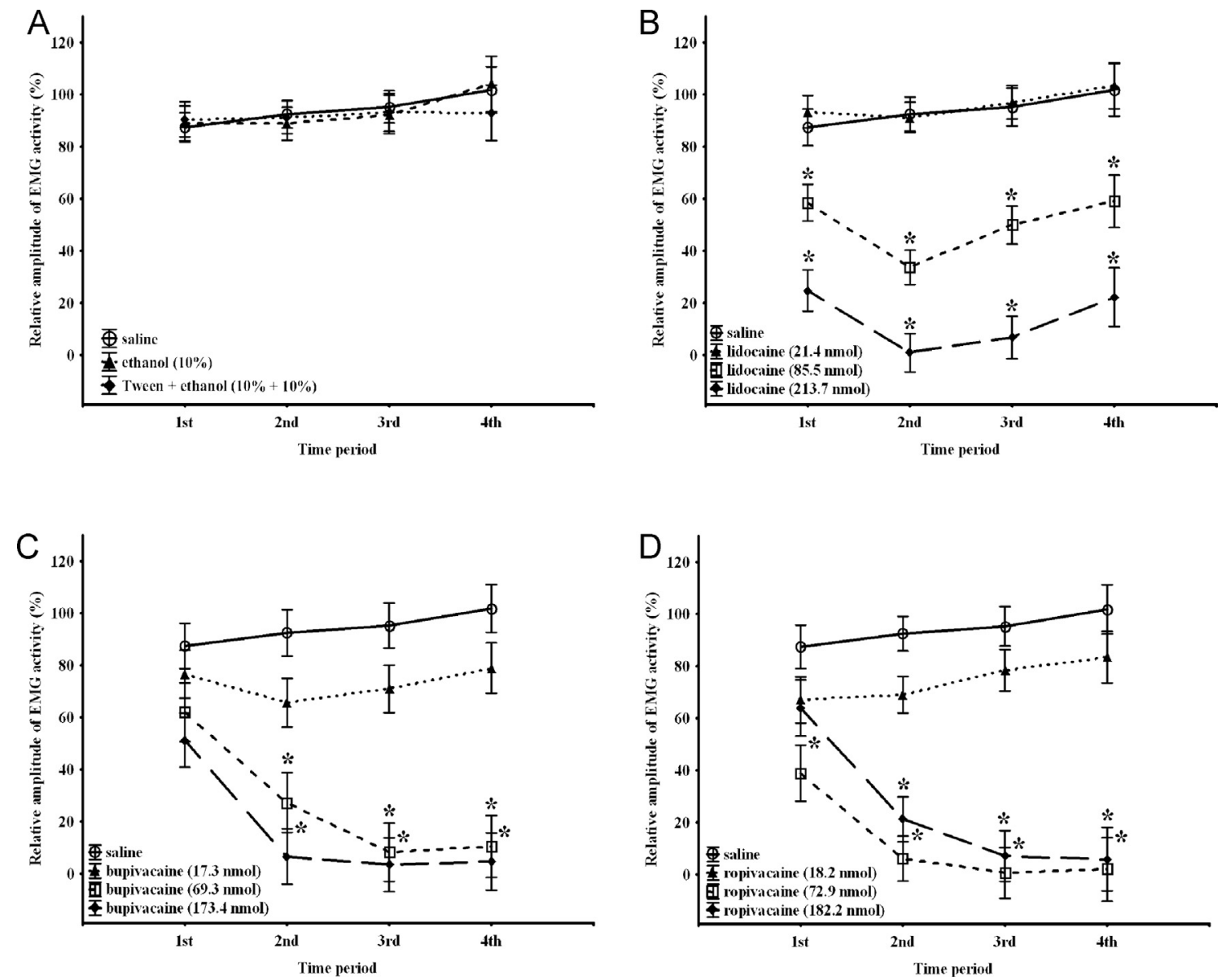

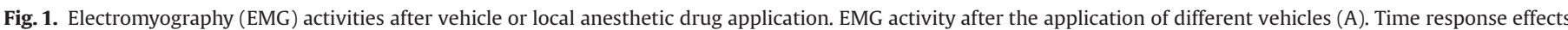

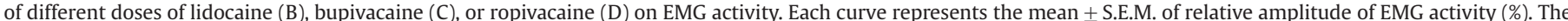

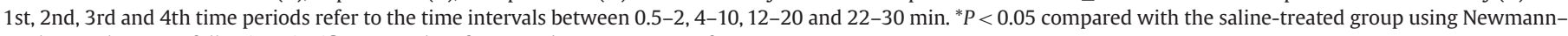
Keuls post-hoc test, following significant results of repeated measurement of ANOVA.

negative one at $2.9 \pm 0.04 \mathrm{~ms}$. The mean baseline amplitude was $2.8 \pm 0.1 \mathrm{mV}$. The analysis of the peak latencies (if any response was detected) did not reveal significant effects of any drug, i.e., peak latencies were not influenced significantly by any treatment (data are not shown); thus, only the amplitude changes were analyzed.

Regarding the effects of lidocaine, significant effects of doses $\left(F_{3,37}=33.6 ; P<0.001\right)$ and time $\left(F_{3,111}=8.3 ; P<0.001\right)$ were observed (Fig. 1B). ANOVA also showed significant effects of doses $\left(F_{3,28}=17.0, P<0.001\right)$, time $\left(F_{3,84}=20.8 ; P<0.001\right)$ and interaction $\left(F_{9,84}=10.0 ; \quad P<0.001\right)$ in case of bupivacaine administrations (Fig. 1C). Similarly, in case of ropivacaine administrations ANOVA also showed significant effects of doses $\left(F_{3,27}=24.3, P<0.001\right)$, time $\left(F_{3,81}=9.8 ; P<0.001\right)$ and interaction $\left(F_{9,81}=9.0 ; P<0.001\right)$ (Fig. 1D). All of these drugs produced prolonged EMG depression in higher doses. The linear regression curves of AUC data showed slight potency differences among these local anesthetic drugs (Fig. 2); thus, the $\mathrm{ED}_{50}$ value was the highest for lidocaine [75.9 (CI: 61.0-93.3) nmol], while bupivacaine [34.7 (CI: 21.1-58.1) nmol] and ropivacaine [36.3 (CI: $23.0-72.3) \mathrm{nmol}]$ had slightly higher potency.

Regarding the effect of QX-314 $(380 \mathrm{nmol})$ by itself, it did not produce any effect on EMG activity (data are not shown); however, coadministration of $190 \mathrm{nmol}$ QX-314 potentiated and prolonged the effects of lidocaine administrated in 21.4 and $85.5 \mathrm{nmol}$ doses (Fig. 3A and B). ANOVA showed significant effects of interaction $\left(F_{3,75}=7.03\right.$; $P<0.001$ ) in case of the lower dose combination, while treatment was close to significant $(P=0.051)$. ANOVA showed significant effects of time $\left(F_{3,51}=6.6 ; P<0.001\right)$ and interaction $\left(F_{3,51}=4.3 ; P<0.01\right)$ in case

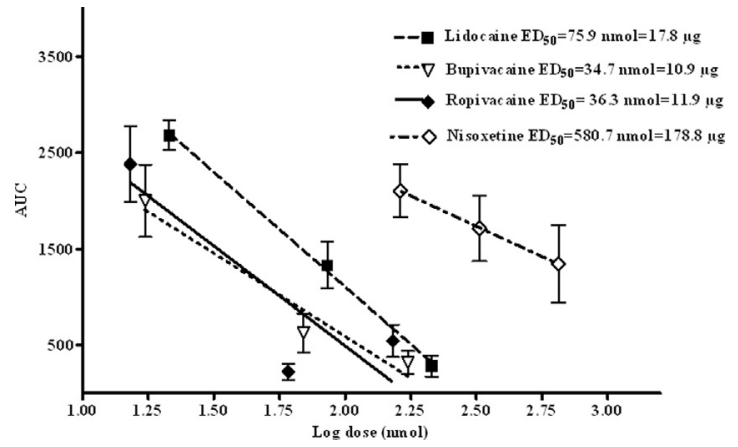

Fig. 2. Area under the curve (AUC) values of local anesthetic drugs. Linear regression curves of AUC values for lidocaine, bupivacaine, ropivacaine and nisoxetine. Each line represents the mean \pm S.E.M. of AUC values.

of the higher dose combination.

Regarding nisoxetine treatment, ANOVA showed significant effects of doses $\left(F_{3,30}=3.5, P<0.05\right)$, time $\left(F_{3,90}=12.0 ; P<0.001\right)$ and interaction $\left(F_{9,90}=4.6 ; P<0.001\right)$ (Fig. 4$)$. The linear regression curves of AUC data showed that nisoxetine had very low potency [ED50: 580.7 (CI: 206.5-1633.1) nmol] compared to the classical local anesthetic drugs (Fig. 2).

Regarding the effects of $\mathrm{AA}$, it did not produce significant inhibition on the evoked action potentials even in high doses (Fig. 5A). ANOVA showed significant effects of doses $\left(F_{4,28}=2.7\right.$, $P<0.05)$ after AEA application; thus, $567 \mathrm{nmol}$ produced about $50 \%$ inhibitory tendency, but the post-hoc analysis did not show 

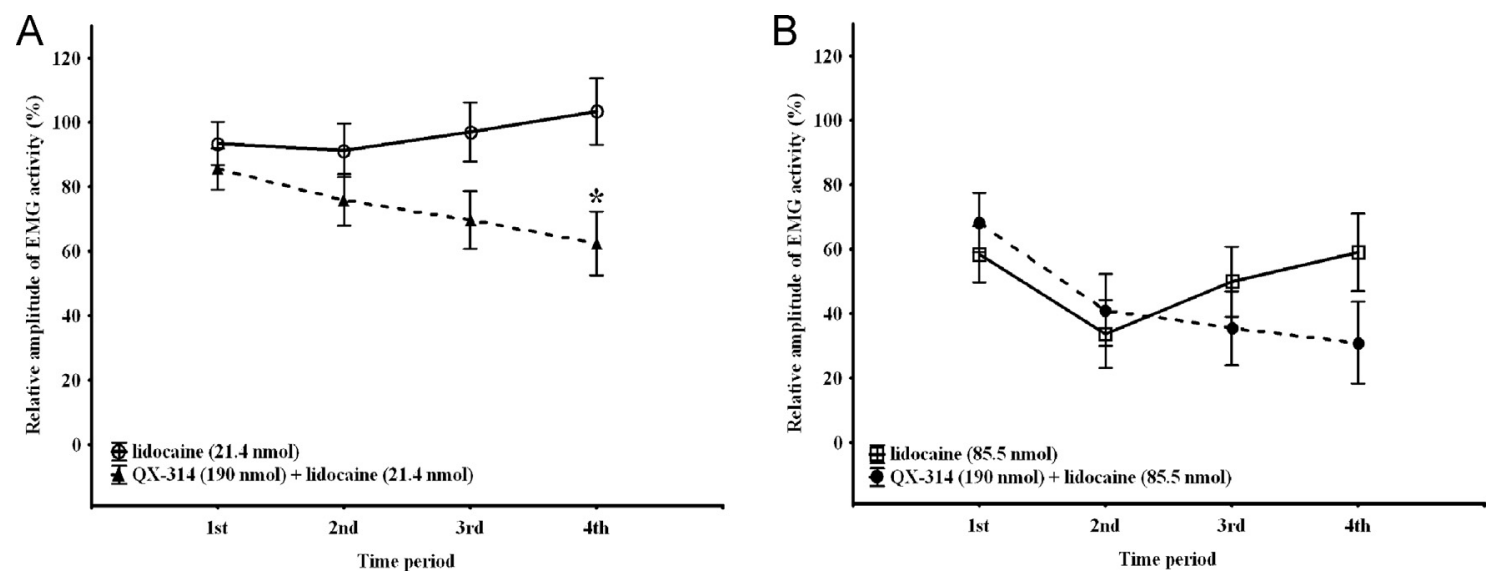

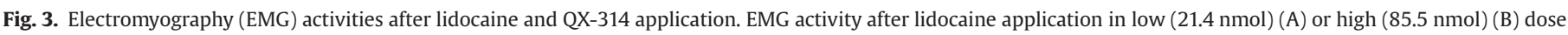

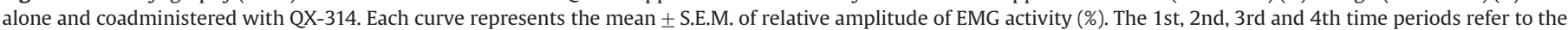

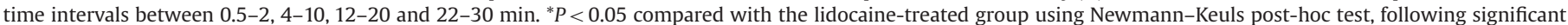
results of repeated measurement of ANOVA.

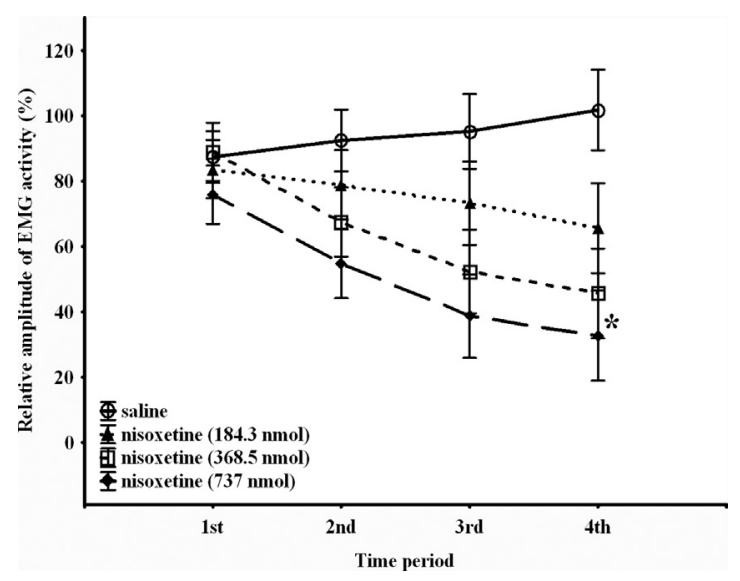

Fig. 4. Electromyography (EMG) activities after nisoxetine application. The timeresponse effect of different doses of nisoxetine on EMG activity. Each curve represents the mean \pm S.E.M. of relative amplitude of EMG activity (\%). The 1st, 2 nd, 3rd and 4th time periods refer to the time intervals between $0.5-2,4-10,12-20$ and $22-30$ min. ${ }^{*} P<0.05$ compared with the saline-treated group using Newmann-Keuls post-hoc test, following significant results of repeated measurement of ANOVA.

significant differences between the vehicle and AEA at any time points (Fig. 5B). In case of capsaicin treatment, ANOVA showed significant effects of doses $\left(F_{3,25}=4.4, P<0.05\right)$, time $\left(F_{3,75}=4.7\right.$; $P<0.005)$ and interaction $\left(F_{9,75}=4.5 ; P<0.001\right)$; thus, $663 \mathrm{nmol}$ produced about $50 \%$ inhibition, and the post-hoc analysis showed significant differences between the vehicle and capsaicin application in the latest time period (Fig. 5C). The linear regression analysis did not show significant dose response for these ligands; therefore, $\mathrm{ED}_{50}$ values could not be calculated.

\section{Discussion}

Our data demonstrated that perineural injection of classical local anesthetic ligands has high potency on nerves containing only motor fibers, suggesting that our model might be a reliable and simple test to investigate the in vivo effects of different molecules via primarily on $\mathrm{Na}_{\mathrm{v}} \mathrm{s}$. Furthermore, nisoxetine had very small efficacy in this model, and QX-314 did not produce any effect on motor fiber function by itself, but it slightly potentiated the effect of lidocaine in agreement with earlier behavioral studies (Binshtok et al., 2009; Brenneis et al., 2014). Our data first revealed the in vivo effects of two unsaturated lipid derivatives on EMG activity of motor fibers. AA was ineffective, while AEA and capsaicin had a modest blocking effect in high but not in the maximal applied dose suggesting that they do not have significant effects on $\mathrm{Na}_{\mathrm{v}} \mathrm{S}$ in vivo circumstances in moderate doses.

It is well-known that the myelin sheath is periodically interrupted by the nodes of Ranvier, regions with a high density of $\mathrm{Na}_{\mathrm{v}} \mathrm{s}$, which generate the spike, and they mediate fast saltatory conduction (Salzer, 2002). Local anesthetics are drugs that produce reversible inhibition of nerve conduction acting on $\mathrm{Na}_{\mathrm{v}}$ in different types of nerve fibers (Butterworth and Strichartz, 1990). Presently, the local anesthetics in clinical use are mainly tertiary amines, and these drugs, under physiological conditions, exist in a mixture of protonated and neutral, uncharged forms (Butterworth and Oxford, 2009; Frazier et al., 1970). The uncharged hydrophobic form can penetrate through the lipid layers of the neuronal cell membrane (Frazier et al., 1970). Once they gain access to the local anesthetic binding site on the cytoplasmic side of the conducting pore of $\mathrm{Na}_{\mathrm{v}} \mathrm{s}$, the protonated form appears to be more potent than the neutral one.

Lidocaine [2-(diethylamino)-N-(2,6-dimethylphenyl)acetamide], bupivacaine [(RS)1-butyl-N-(2,6-dimethylphenyl)piperidine-2-carboxamide] and ropivacaine [(S)- $N$-(2,6-dimethylphenyl)-1-propylpiperidine-2-carboxamide] are widely used local anesthetic drugs (Nakagawa and Hiura, 2013). We found slight potency differences between these drugs; i.e., bupivacaine and ropivacaine had almost the same potency on EMG activity, and this was slightly higher compared to lidocaine (Sisk, 1992). These results are in agreement with data on human subjects, and partially, with their lipid solubility; i.e., the octanol/buffer partition coefficient of lidocaine is the lowest, which might lead to its lower potency (Strichartz et al., 1990). Since other class 1 antiarrhythmic drugs such as quinidine also inhibited the evoked compound muscle action potentials, we suppose that our model might be capable to display some intermediate degree of actions mediated by $\mathrm{Na}_{\mathrm{v}} \mathrm{s}$ (Cheng et al., 2014).

As it was mentioned in the Introduction, QX-314 can produce selective inactivation of $\mathrm{Na}_{\mathrm{v}} \mathrm{S}$ in sensory neurons by entering the cells through TRP channels; therefore, its topical administration alone does not influence the motor functions (Binshtok et al., 2007, 2009; Kim et al., 2010; Shen et al., 2012). However, its perisciatic application in very high doses can produce temporary motor impairments (Lim et al., 2007; Roberson et al., 2011). Until now only one study has recorded the EMG activity from the digastric muscle to painful stimuli of the dental cavity after QX-314 

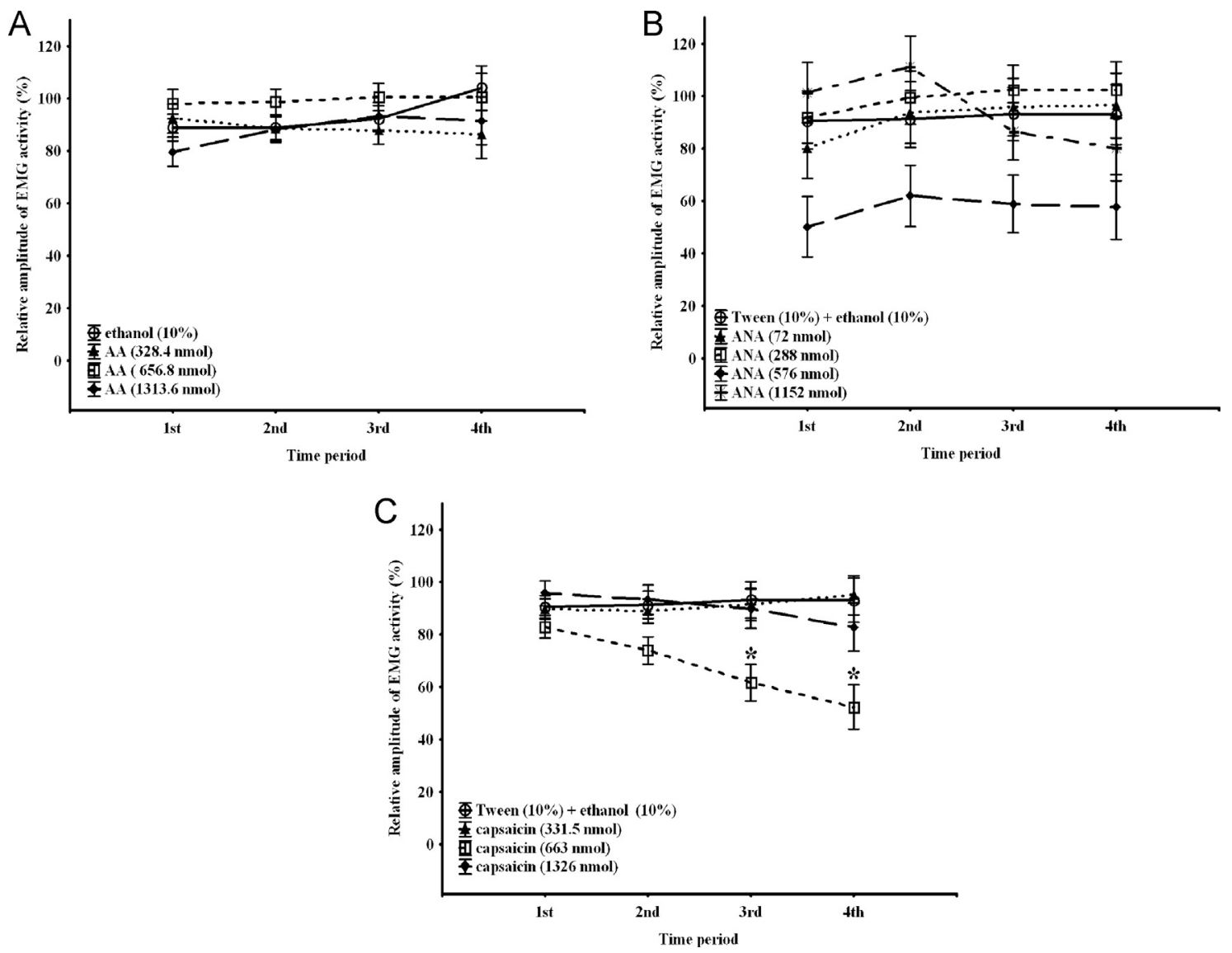

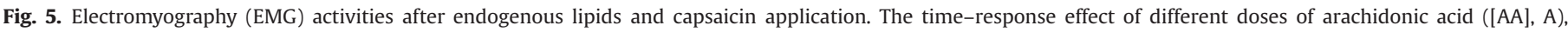

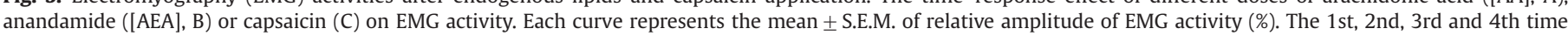

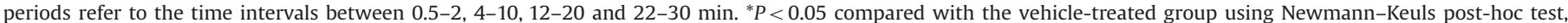
following significant results of repeated measurement of ANOVA.

administration: QX-314 did not influence the mylohyoid motor nerve activity, which is perfectly agreement with our results (Kim et al., 2010). Regarding the effects of QX-314 with bupivacaine or lidocaine, a prolonged motor paralysis has been observed after their perisciatic (mixed nerve) administrations (Binshtok et al., 2009; Brenneis et al., 2014; Roberson et al., 2011) similarly to our present results. Since QX-314 cannot influence the $\mathrm{Na}_{\mathrm{v}}$ extracellularly, pharmacokinetic interaction between the two ligands such as their binding to plasma proteins can modify the elimination of lidocaine (Taheri et al., 2003). Furthermore, it has been recently shown that bupivacaine and lidocaine can cause QX-314 accumulation in cells which do not express TRPV1 or TRPA1 channels, and it also induces a prolonged block of C-fibers of isolated sciatic nerves in TRPA1-TRPV1 double knockout mice (Brenneis et al., 2014). Furthermore, the analgesia and motor block produced by the co-application of bupivacaine and QX-314 to rat sciatic nerve is not abolished by ruthenium red (TRP channel blocker). It is suggested that the mechanism of this potentiation is most likely relies on the interaction of the local anesthetics and the lipid bilayer itself (Brenneis et al., 2014), but further experiments are required to reveal the exact mechanism of their interaction.

Some data show that nisoxetine, [(RS)-3-(2-methoxyphenoxy)$\mathrm{N}$-methyl-3-phenylpropan-1-amine], inhibits $\mathrm{Na}_{\mathrm{v}} \mathrm{s}$ in vitro models and also produces dose dependent blockade during spinal anesthesia in rats (Hennings et al., 1999; Leung et al., 2013). Chen et al. (2012) have compared the local anesthetic effect of nisoxetine with lidocaine in the cutaneous trunci muscle reflex, and nisoxetine had high inhibitory potency, suggesting that both drugs inhibit $\mathrm{Na}_{\mathrm{V}} \mathrm{S}$ on sensory axons. In contrast to these findings, we found very low potency of nisoxetine on motor fibers, which is in agreement with the in vitro results (Hennings et al., 1999; Leung et al., 2013). The controversy might be due to the differences in the applied model as the earlier study investigated only the sensory functions (Chen et al., 2012). It might be supposed that the structural differences between the motor and sensory fibers could result in decreased potency in motor fibers, which might be beneficial in clinical circumstances (Krishnan et al., 2009).

Functional studies suggest that TRPV1 and cannabinoid receptors are expressed peripherally on (primarily unmyelinated) sensory fibers (Bernardini et al., 2004; Domoki et al., 2003; Gamse et al., 1982; Sann et al., 1995; Santha and Jancso, 2003; Sauer and Reeh, 2009; Tominaga et al., 1998). Therefore, perineural capsaicin and AEA can influence the activity of these fibers by acting on these receptors. There is no proof about the presence of TRPV1 or cannabinoid receptors on motor fibers, and perineural application of capsaicin does not influence the activity of myelinated fibers (Brenneis et al., 2013; Petsche et al., 1983; Weller et al., 2011). Since most of the peripheral nerves (e.g., the sciatic nerve) contain both sensory and motor fibers, it would be difficult to distinguish between the effects on TRPV1/ cannabinoid CB1 receptors and $\mathrm{Na}_{\mathrm{v}} \mathrm{s}$. As earlier in vitro results showed, AA and AEA can inhibit $\mathrm{Na}_{\mathrm{v}}$ in high doses by a hyperpolarizing shift of the steady-state inactivation voltage independently of cannabinoid receptor activations (Al Kury et al., 2014; Boland and Drzewiecki, 2008; Fang et al., 2011; Lee et al., 2002; Nicholson et al., 2003). It was also suggested that AEA-induced antinociception in cannabinoid $\mathrm{CB} 1$ receptor knockout mice might have been due to the state-dependent inhibition of sodium currents in sensory neurons 
(Di Marzo et al., 2000). In vitro studies have presented that capsaicin also inhibits $\mathrm{Na}_{\mathrm{v}} \mathrm{s}$ at a high concentration $(>10 \mu \mathrm{M}$ ) (Abel et al., 2003; Cao et al., 2007; Duan et al., 2007; Lundbaek et al., 2005; Nicholson et al., 2003; Wang et al., 2007; Yamanaka et al., 1984). These effects could be observed in TRPV1 knockout mice and TRPV1 antagonist independent manner, even the TRPV1 receptor antagonist, capsazepine, causes similar effects as capsaicin (Cao et al., 2007; Lundbaek et al., 2005; Wang et al., 2007). Since our model investigates a nerve containing only motor fibers, it can be an appropriate model for examining primarily $\mathrm{Na}_{\mathrm{v}} \mathrm{s}$-mediated effects (Fundin et al., 1994; Semba and Egger, 1986). In contrast to the in vitro results, our in vivo data showed that AA could not produce any effect on the motor nerve activity, which might be due to its low potency and/or fast metabolism. Both AEA and capsaicin caused slight inhibition on EMG activity in high doses (capsaicin: $663 \mathrm{nmol}$; AEA: $576 \mathrm{nmol}$ ), but their largest applied doses (capsaicin: 1326 nmol; AEA: 1152 nmol) were ineffective. We cannot give an explanation for this phenomenon, but these highly lipophylic ligands could alter the lipid bilayer elasticity; thus, a stiffening of the membrane can cause conformational changes in the channel proteins leading to alteration in the function of $\mathrm{Na}_{\mathrm{v}} \mathrm{S}$ at special doses (Duan et al., 2007, 2008; Jiang and Gonen, 2012; Lundbaek et al., 2005).

Since these effective doses were very high, their pharmacological utilization is questionable.Since local anesthetic drugs, lipids and capsaicin can also inhibit voltage-gated potassium channels, located primarily paranodally, with very low potencies, it cannot be excluded that the inhibition of these channels might partially mask $\mathrm{Na}_{\mathrm{v}} \mathrm{S}$-mediated effects (Boland and Drzewiecki, 2008; Borchard and Drouin, 1980; Dubois, 1982; Evans et al., 2008; Jiang and Gonen, 2012; Krishnan et al., 2009; Kuenzi and Dale, 1996; Matsumoto et al., 2010). In conclusion, we demonstrated that our in vivo model is an appropriate and reproducible interdisciplinary test to investigate the $\mathrm{Na}_{\mathrm{v}}$-mediated effects of different molecules. In vivo models offer certain advantages over in vitro studies since they might have more relevance to clinical conditions. The inefficiency or very low potency of lipids and capsaicin on motor fibers suggests that the observed effects on peripheral neurons in lower doses might not be due to the effects on $\mathrm{Na}_{\mathrm{v}} \mathrm{s}$.

\section{Acknowledgment}

This work was supported by the Hungarian Scientific Research Fund (OTKA, K83810) and TÁMOP-4.2.2.A-11/1KONV-2012-0052. The authors wish to thank Agnes Tandari for her excellent technical assistance. The authors declare no competing financial interests.

\section{References}

Abel, K.M., Allin, M.P. Hemsley, D.R., Geyer, M.A, 2003, Low dose ketamine increases prepulse inhibition in healthy men. Neuropharmacology 44, 729-737.

Al Kury, L.T., Vojtechova, O.I., Yang, K.H., Thayyullathil, F.T., Doroshenko, P., Ramirez A.M., Shuba, Y.M., Galadari, S., Howarth, F.C., Oz, M., 2014. Effects of the endogenous cannabinoid anandamide on voltage-dependent sodium and calcium channels in rat ventricular myocytes. Br. J. Pharmacol. 171, 3485-3498.

Bernardini, N., Neuhuber, W., Reeh, P.W., Sauer, S.K., 2004. Morphological evidence for functional capsaicin receptor expression and calcitonin gene-related peptide exocytosis in isolated peripheral nerve axons of the mouse. Neuroscience $126,585-590$.

Binshtok, A.M., Bean, B.P., Woolf, C.J., 2007. Inhibiton of nociceptors by TRPV1mediated entry of impermeant sodium channel blockers. Nature 449, 607-611.

Binshtok, A.M., Gerner, P., Oh, S.B., Puopolo, M., Suzuki, S., Roberson, D.P., Herbert T., Wang, C.F., Kim, D., Chung, G., Mitani, A.A., Wang, G.K., Bean, B.P., Woolf, C.J. 2009. Coapplication of lidocaine and the permanently charged sodium channe blocker QX-314 produces a long-lasting nociceptive blockade in rodents. Anesthesiology 111, 127-137.

Boland, L.M., Drzewiecki, M.M., 2008. Polyunsaturated fatty acid modulation of voltage-gated ion channels. Cell Biochem. Biophys. 52, 59-84.
Borchard, U., Drouin, H., 1980. Caricaine: action of the local anesthetic on myelinated nerve fibres. Eur. J. Pharmacol. 62, 73-79.

Brenneis, C., Kistner, K., Puopolo, M., Jo, S., Roberson, D.P., Sisignano, M., Segal, D., Cobos, E.J., Wainger, B.J., Labocha, S., Ferreir+-s, N., von Hehn, C., Tran, J., Geisslinger, G., Reeh, P.W., Bean, B.P., Woolf, C.J., 2014. Bupivacaine-induced cellular entry of QX-314 and its contribution to differential nerve block. Br. J. Pharmacol. 171, 438-451.

Brenneis, C., Kistner, K., Puopolo, M., Segal, D., Roberson, D., Sisignano, M., Labocha, S., Ferreiros, N., Strominger, A., Cobos, E.J., Ghasemlou, N., Geisslinger, G., Reeh, P.W., Bean, B.P., Woolf, C.J., 2013. Phenotyping the function of TRPV1-expressing sensory neurons by targeted axonal silencing. J. Neurosci. 33, 315-326.

Bucher, D., Goaillard, J.M., 2011. Beyond faithful conduction: short-term dynamics, neuromodulation, and long-term regulation of spike propagation in the axon. Prog. Neurobiol. 94, 307-346.

Butterworth, J., Oxford, G.S., 2009. Local anesthetics: a new hydrophilic pathway for the drug-receptor reaction. Anesthesiology 111, 12-14.

Butterworth, J.F., Strichartz, G.R., 1990. Molecular mechanisms of local anesthesia: a review. Anesthesiology 72, 711-734

Cao, X., Cao, X., Xie, H., Yang, R., Lei, G., Li, F., Li, A., Liu, C., Liu, L., 2007. Effects of capsaicin on VGSCs in TRPV1-1- mice. Brain Res. 1163, 33-43.

Chen, Y.W., Chu, C.C., Chen, Y.C., Wang, J.J., Hung, C.H., Shao, D.Z., 2012. Nisoxetine produces local but not systemic analgesia against cutaneous nociveptive stimuli in the rat. Eur. J. Pharmacol. 675, 22-25.

Cheng, K.I., Lin, I.L., Chang, L.L., Jou, I.M., Lai, C.S., Wang, J.J., Wang, H.C., Kwan, A.L., 2014. Application of quinidine on rat sciatic nerve decreases the amplitude and increases the latency of evoked responses. J. Anesth. 28, 559-568.

Di Marzo, V., Breivogel, C.S., Tao, Q., Bridgen, D.T., Razdan, R.K., Zimmer, A.M., Zimmer, A., Martin, B.R., 2000. Levels, metabolism, and pharmacological activity of anandamide in $\mathrm{CB}_{1}$ cannabinoid receptor knockout mice. Evidence for non- $\mathrm{CB}_{1}$, non- $\mathrm{CB}_{2}$ receptor-mediated actions of anandamide in mouse brain. J. Neurochem. 75, 2434-2444.

Domoki, F., Santha, P., Bari, F., Jancso, G., 2003. Perineural capsaicin treatment at tenuates reactive hyperaemia in the rat skin. Neurosci. Lett. 341, 127-130.

Duan, Y., Zheng, J., Nicholson, R.A., 2007. Vanilloid (subtype 1) receptor-modulatory drugs inhibit $\left[{ }^{3} \mathrm{H}\right]$ batrachotoxinin-A 20-alfa-benzoate binding to $\mathrm{Na}^{+}$channels. Basic Clin. Pharmacol. Toxicol. 100, 91-95.

Duan, Y., Zheng, J., Nicholson, R.A., 2008. Inhibition of $\left[{ }^{3} \mathrm{H}\right]$ batrachotoxinin A-20alpha-benzoate binding to sodium channels and sodium channel function by endocannabinoids. Neurochem. Int. 52, 438-446.

Dubois, J.M., 1982. Capsaicin blocks one class of $\mathrm{K}^{+}$channels in the frog node of Ranvier. Brain Res. 245, 372-375.

Evans, R.M., Wease, K.N., MacDonald, C.J., Khairy, H.A., Ross, R.A., Scott, R.H., 2008. Modulation of sensory neuron potassium conductances by anandamide indicates roles for metabolites. Br. J. Pharmacol. 154 (2), 480-492.

Fang, Y.J., Zhou, M.H., Gao, X.F., Gu, H., Mei, Y.A., 2011. Arachidonic acid modulates $\mathrm{Na}+$ currents by non-metabolic and metabolic pathways in rat cerebellar granule cells. Biochem. J. 438, 203-215.

Frazier, D.T., Narahashi, T., Yamada, M., 1970. The site of action and active form of local anethetics. II. Experiments with quaternary compounds. J. Pharmacol. Exp. Ther. 171, 45-51.

Fundin, B.T., Rice, F.L., Pfaller, K., Arvidsson, J., 1994. The innervation of the mystacial pad in the adult-rat studied by anterograde transport of HRP conjugates. Exp. Brain Res. 99, 233-246.

Gamse, R., Petsche, U., Lembeck, F., Jancso, G., 1982. Capsaicin applied to periphera nerve inhibits axoplasmic transport of substance P and somatostatin. Brain Res. 239, 447-462.

Hennings, E.C.P., Kiss, J.P., De Oliveira, K., Toth, P.T., Vizi, E.S., 1999. Nicotinic acetylcholine receptor antagonistic activity of monoamine uptake blockers in rat hippocampal slices. J. Neurochem. 73, 1043-1050.

Jiang, Q.X., Gonen, T., 2012. The influence of lipids on voltage-gated ion channels Curr. Opin. Struct. Biol. 22, 529-536.

Kim, H.Y., Kim, K., Li, H.Y., Chung, G., Park, C.K., Kim, J.S., Jung, S.J., Lee, M.K., Ahn, D. K., Hwang, S.J., Kang, Y., Binshtok, A.M., Bean, B.P., Woolf, C.J., Oh, S.B., 2010. Selectively targeting pain in the trigeminal system. Pain 150, 29-40.

Krishnan, A.V., Lin, C.S.Y., Park, S.B., Kiernan, M.C., 2009. Axonal ion channels from bench to bedside: a translational neuroscience perspective. Prog. Neurobiol. 89, $288-313$.

Kuenzi, F.M., Dale, N., 1996. Effect of capsaicin and analogues on potassium and calcium currents and vanilloid receptors in xenopus embryo spinal neurones. Br. J. Pharmacol. 119, 81-90.

Lee, G.Y., Shin, Y.K., Lee, C.S., Song, J.H., 2002. Effects of arachidonic acid on sodium currents in rat dorsal root ganglion neurons. Brain Res. 950, 95-102.

Leung, Y.M., Chu, C.C., Kuo, C.S., Chen, Y.W., Wang, J.J., 2013. Nisoxetine blocks sodium currents and elicits spinal anesthesia in rats. Pharmacol. Rep. 65, 350-357.

Lim, T.K.Y., MacLeod, B.A., Ries, C.R., Schwarz, S.K.W., 2007. The quaternary lidocaine derivative, QX-314, produces long-lasting local anesthesia in animal models in vivo. Anesthesiology 107, 305-311.

Liu, H., Zhang, H.X., Hou, H.Y., Lu, X.F., Wei, J.Q., Wang, C.G., Zhang, L.C., Zeng, Y.M., Wu, Y.P., Cao, J.L., 2011. Acid solution is a suitable medium for introducing QX314 into nociceptors through TRPV1 channels to produce sensory-specific analgesic effects. PLoS One 6, e29395.

Lundbaek, J.A., Birn, P., Tape, S.E., Toombes, G.E.S., Sogaard, R., Koeppe II, R.E., Gruner, S.M., Hansen, A.J., Andersen, O.S., 2005. Capsaicin regulates voltagedependent sodium channels by altering lipid bilayer elasticity. Mol. Pharmacol. 68, 680-689. 
164

A. Safrany-Fark et al. / European Journal of Pharmacology 762 (2015) 158-164

Mechoulam, R., Ben Shabat, S., Hanus, L., Ligumsky, M., Kaminski, N.E., Schatz, A.R., Gopher, A., Almog, S., Martin, B.R., Compton, 1995. Identification of an endogenous 2-monoglyceride, present in canine gut, that binds to cannabinoid receptors. Biochem. Pharmacol. 50, 83-90.

Matsumoto, S., Yoshida, S., Takahashi, M., Saiki, C., Takeda, M., 2010. The roles of I (D), I(A) and $\mathrm{I}(\mathrm{K})$ in the electrophysiological functions of small diameter rat trigeminal ganglion neurons. Curr. Mol. Pharmacol. 3, 30-36.

Nakagawa, H., Hiura, A., 2013. Comparison of the transport of QX-314 through TRPA1, TRPM8, and TRPV1 channels. J. Pain Res. 6, 223-230.

Nicholson, R.A., Liao, C., Zheng, J., David, L.S., Coyne, L., Errington, A.C., Singh, G., Lees, G., 2003. Sodium channel inhibition by anandamide and synthetic cannabimimetics in brain. Brain Res. 978, 194-204.

Petsche, U., Fleischer, E., Lembeck, F., Handwerker, H.O., 1983. The effect of capsaicin application to a peripheral nerve on impulse conduction in functionally identified afferent nerve fibres. Brain Res. 265, 233-240.

Roberson, D.P., Binshtok, A.M., Blasl, F., Bean, B.P., Woolf, C.J., 2011. Targeting of sodium channel blockers into nociceptors to produce long-duration analgesia: a systematic study and review. Br. J. Pharmacol. 164, 48-58.

Salzer, J.L., 2002. Nodes of ranvier come of age. Trends Neurosci. 25, 2-5.

Sann, H., Jancso, G., Rossler, W., Pierau, F.K., 1995. Reduction of substance P binding sites in the spinal dorsal horn after perineural capsaicin treatment in the rat. Neurosci. Lett. 190, 151-154.

Santha, P., Jancso, G., 2003. Transganglionic transport of choleragenoid by capsaicin-sensitive C-fibre afferents to the substantia gelatinosa of the spinal dorsal horn after peripheral nerve section. Neuroscience 116, 621-627.

Sauer, S.K., Reeh, P.W., 2009. Inflammation and hypersensitivity in the context of the sensory functions of axonal membranes: what are the molecular mechanisms? Dig. Dis. 27 (Suppl. 1), S11-S15.

Semba, K., Egger, M.D., 1986. The facial "motor" nerve of the rat: control of vibrissal movement and examination of motor and sensory components. J. Comp.
Neurol. 247, 144-158.

Shen, J., Fox, L.E., Cheng, J.G., 2012. Differential effects of peripheral versus central coadministration of QX-314 and capsaicin on neuropathic pain in rats. Anesthesiology 117, 365-380.

Sisk, A.L., 1992. Long-acting local anesthetics in dentistry. Anesth. Prog. 39, 53-60. Strichartz, G.R., 1973. The inhibition of sodium currents in myelinated nerve by quaternary derivatives of lidocaine. J. Gen. Physiol. 62, 37-57.

Strichartz, G.R., Sanchez, V., Arthur, G.R., Chafetz, R., Martin, D., 1990. Fundamental properties of local anesthetics. II. measured octanol: buffer partition coefficients and pKa values of clinically used drugs. Anesth. Analg. 71, 158-170.

Taheri, S., Cogswell, L.P., Gent, A., Strichartz, G.R., 2003. Hydrophobic and ionic factors in the binding of local anesthetics to the major variant of human alpha1-acid glycoprotein. J. Pharmacol. Exp. Ther. 304, 71-80.

Tominaga, M., Caterina, M.J., Malmberg, A.B., Rosen, T.A., Gilbert, H., Skinner, K., Raumann, B.E., Basbaum, A.I., Julius, D., 1998. The cloned capsaicin receptor integrates multiple pain-producing stimuli. Neuron 21, 531-543.

Wang, S.Y., Mitchell, J., Wang, G.K., 2007. Preferential block of inactivation-deficient $\mathrm{Na}^{+}$currents by capsaicin reveals a non-TRPV1 receptor within the $\mathrm{Na}^{+}$ channel. Pain 127, 73-83.

Weller, K., Reeh, P.W., Sauer, S.K., 2011. TRPV1, TRPA1, and CB1 in the isolated vagus nerve - axonal chemosensitivity and control of neuropeptide release. Neuropeptides 45, 391-400.

Yamanaka, K., Kigoshi, S., Muramatsu, I., 1984. Conduction-block induced by capsaicin in crayfish giant axon. Brain Res. 300, 113-119.

Yokogawa, F., Kiuchi, Y., Ishikaw, Y., Otsuka, N., Masuda, Y., Oguchi, K., Hosoyamada, A., 2002. An investigation of monoamine receptors involved in antinociceptive effects of antidepressants. Anesth. Analg. 95, 163-168. 